Review

\title{
Flux-Grown Piezoelectric Materials: Application to $\alpha$-Quartz Analogues
}

\author{
Pascale Armand*, Adrien Lignie, Marion Beaurain and Philippe Papet \\ Institut Charles Gerhardt Montpellier, UMR5253, CNRS-UM2-ENSCM-UM1, C2M, UMII, CC 1504, \\ Place E. Bataillon, 34095 Montpellier Cedex 5, France; E-Mails: adrien.lignie@ univ-montp2.fr (A.L.); \\ marion@artimachines.com (M.B.); philippe.papet@univ-montp2.fr (P.P.)
}

* Author to whom correspondence should be addressed; E-Mail: pascale.armand@univ-montp2.fr; Tel.: +33-4-67-14-33-19; Fax: +33-4-67-14-42-90.

Received: 22 April 2014; in revised form: 11 June 2014 / Accepted: 12 June 2014 /

Published: 23 June 2014

\begin{abstract}
Using the slow-cooling method in selected $\mathrm{MoO}_{3}$-based fluxes, single-crystals of $\mathrm{GeO}_{2}$ and $\mathrm{GaPO}_{4}$ materials with an $\alpha$-quartz-like structure were grown at high temperatures $\left(T \geq 950{ }^{\circ} \mathrm{C}\right)$. These piezoelectric materials were obtained in millimeter-size as well-faceted, visually colorless and transparent crystals. Compared to crystals grown by hydrothermal methods, infrared and Raman measurements revealed flux-grown samples without significant hydroxyl group contamination and thermal analyses demonstrated a total reversibility of the $\alpha$-quartz $\leftrightarrow \beta$-cristobalite phase transition for $\mathrm{GaPO}_{4}$ and an absence of phase transition before melting for $\alpha-\mathrm{GeO}_{2}$. The elastic constants $C_{I J}$ (with $I, J$ indices from 1 to 6 ) of these flux-grown piezoelectric crystals were experimentally determined at room and high temperatures. The ambient results for as-grown $\alpha-\mathrm{GaPO}_{4}$ were in good agreement with those obtained from hydrothermally-grown samples and the two longitudinal elastic constants measured versus temperature up to $850{ }^{\circ} \mathrm{C}$ showed a monotonous evolution. The extraction of the ambient piezoelectric stress contribution $\mathrm{e}_{11}$ from the $C^{\mathrm{D}}{ }_{11}$ to $C^{\mathrm{E}}{ }_{11}$ difference gave for the piezoelectric strain coefficient $d_{11}$ of flux-grown $\alpha-\mathrm{GeO}_{2}$ crystal a value of 5.7(2) $\mathrm{pC} / \mathrm{N}$, which is more than twice that of $\alpha$-quartz. As the $\alpha$-quartz structure of $\mathrm{GeO}_{2}$ remained stable up to melting, a piezoelectric activity was observed up to $1000^{\circ} \mathrm{C}$.
\end{abstract}

Keywords: single crystal; $\mathrm{GaPO}_{4} ; \mathrm{GeO}_{2} ; \mathrm{SiO}_{2}$; raman; infrared; Brillouin; growth from high temperature solution; differential scanning calorimetry (DSC); X-ray diffraction 


\section{Introduction}

Piezoelectric materials that can operate under very high temperature without degradation are sought for the control of structure materials and control system in turbines, engines, nuclear reactors, etc. [1,2]. However, the use of a piezoelectric material at elevated temperature presents many challenges such as possible phase transition, chemical degradation or structural defect propagation which can cancel or lead to instability of the piezoelectric properties.

Non-pyroelectric single crystals with the $\alpha$-quartz-like structure exhibiting both higher piezoelectric constants and a higher thermal stability as compared to $\alpha$-quartz would be promising materials to build miniaturized high temperature piezoelectric-operated devices without cooling. In the $\mathrm{XO}_{2}(\mathrm{X}=\mathrm{Si}, \mathrm{Ge})$ and $\mathrm{MPO}_{4}(\mathrm{M}=\mathrm{Fe}, \mathrm{Al}, \mathrm{Ga}, \mathrm{B})$ family, the $\alpha$-quartz-like structure is composed of either only $\mathrm{XO}_{4}$ corner-shared tetrahedra or of both $\mathrm{MO}_{4}$ and $\mathrm{PO}_{4}$ tetrahedra forming a trigonal system [3-16]. The $\alpha$-phase $\left(P 3_{1} 21\right.$ or $P 3_{2} 21$, respectively left-handed or right-handed, $\left.Z=3\right)$ is derived from the $\beta$-phase $\left(P 6_{2} 22\right.$ or $\left.P 6_{4} 22\right)$ by a symmetry loss induced by a tilt of the tetrahedra around the $b$-axis. Two structural distortion parameters exist to quantify this phenomenon: the average intertetrahedral bridging angle $\theta$ $(\mathrm{X}-\mathrm{O}-\mathrm{X}$ or $\mathrm{M}-\mathrm{O}-\mathrm{P})$ and the tetrahedral tilt angle $\delta[11,14,17-20]$. Based on experimental characterizations and theoretical studies on $\alpha$-quartz analogues, it was demonstrated that the higher piezoelectric properties of $\alpha-\mathrm{GaPO}_{4}$ and $\alpha-\mathrm{GeO}_{2}$ materials compared to $\alpha-\mathrm{SiO}_{2}, \alpha-\mathrm{FePO}$ and $\alpha-\mathrm{AlPO}_{4}$ compounds were directly related to their structural distortion with respect to the $\beta$-quartz structure type (for $\beta-\mathrm{SiO}_{2} \theta=153.3^{\circ}$ and $\delta=0^{\circ}$ at $575^{\circ} \mathrm{C}$ ) $[11,14,17,21-27]$.

In addition, the well-known $\alpha-\beta$ phase transition, which appears around $573{ }^{\circ} \mathrm{C}$ in $\alpha-\mathrm{SiO}_{2}$ $\left(\theta=144.2^{\circ}\right)[19,26]$ does not occur when the tilt angle $\delta$ is over $22^{\circ}$ (leading to $\theta$ under $\left.136^{\circ}\right)[9,13,14,22,25]$. In other words, the transition from an $\alpha$ phase to a $\beta$ phase is absent for $\alpha-\mathrm{GeO}_{2}$ and $\alpha-\mathrm{GaPO}_{4}$ crystallized materials $\left(\theta=130.04^{\circ}\right.$ and $\theta=134.60^{\circ}$, respectively) $[13,14,17,22,28,29]$.

Under ambient conditions, $\mathrm{GeO}_{2}$ exhibits two persistent forms of differing anion coordination around the central cation: the $\alpha$-quartz-type modification (trigonal) with $4: 2$ coordination [16] and the rutile-type modification (tetragonal $P 4_{2} / \mathrm{mnm}, Z=2$ ) with $6: 3$ coordination $[4,11,30-34]$. Naturally occurring, $\mathrm{GeO}_{2}$ is known to be more stable in the rutile structure than in the $\alpha$-quartz structure. The transformation from the rutile-like form to the $\alpha$-quartz-type form has been reported to occur under normal atmospheric pressure in the $1024-1045{ }^{\circ} \mathrm{C}$ temperature range [11,35]. The kinetics of the allotropic transformation from a trigonal to a tetragonal structure is extremely low, and non-appreciable without the presence of any catalyst such as traces of $\mathrm{GeO}_{2}$ rutile-like form, chlorides or water [11,36-39].

A transition from the thermodynamically stable $\alpha$-quartz-like $\mathrm{GaPO}_{4}$ phase to the $\beta$-cristobalite modification is known to occur above $960{ }^{\circ} \mathrm{C}$ [13,40-46]. This high temperature allotropic transition does not permit the growth of $\alpha-\mathrm{GaPO}_{4}$ crystals by conventional melt techniques. Single crystals of $\alpha-\mathrm{GaPO}_{4}$ were grown using epitaxial hydrothermal-based methods in a retrograde-solubility range at $T<250{ }^{\circ} \mathrm{C}$ and in the range of direct temperature dependence of solubility at $T>300{ }^{\circ} \mathrm{C}$ from highly corrosive acid solutions [40,43,47-62]. However, for gallium orthophosphate material, it seems quite difficult to obtain very high quality crystals with these solution-based growth methods. The presence of twins, dislocations and/or a quite high level of hydroxyl group incorporated via the growth medium tend to deteriorate the piezoelectric properties especially at high temperatures as physical properties are very sensitive to material perfection $[43,49,50,57,63-73]$. The $\mathrm{OH}$ impurities in $\alpha-\mathrm{GaPO}_{4}$ single crystals are 
responsible for the "milky" appearance of the samples when exposed to high temperature $\left(600{ }^{\circ} \mathrm{C}\right)$. This typical behavior is due to water trace precipitation effects and corresponds to the upper temperature limit of physical property measurements [65,69,74,75].

For $\mathrm{GeO}_{2}$, the temperature region of existence of the stable trigonal phase goes from $1033{ }^{\circ} \mathrm{C}$ up to the melting point of $1116^{\circ} \mathrm{C}[25,30,76]$. When epitaxially-grown in the temperature region where it is metastable, the hydrothermally-grown alpha-quartz form of $\mathrm{GeO}_{2}$ contains high $\mathrm{OH}$ impurities which rather easily catalyze its return to the thermodynamically stable rutile-like structure when heated as low as $180{ }^{\circ} \mathrm{C}$ [77-81].

In this context, it appeared that another suitable growth technique for oxides could be applied for the crystallization of $\alpha-\mathrm{GaPO}_{4}$ and $\alpha-\mathrm{GeO}_{2}$ materials to get single crystals with a high degree of structural and chemical perfection; the high temperature solution growth technique also known as the fluxed melt growth [82-85]. Using molten inorganic salts, or flux, playing the role of solvent, crystals of a compound can be obtained below its melting or transformation point. The principle of flux growth is based on the spontaneous nucleation that occurs when a supersaturation is obtained either upon cooling of a high temperature solution or by boiling away a volatile solvent at a fixed temperature [86]. The fluxed melt method presents some advantages compared to hydrothermal-based growth methods: the material can be crystallized at atmospheric pressure and the inorganic solvents used are water-free at high temperature.

This paper presents an overview of the main results obtained from several structural and physical characterizations undertaken on flux-grown $\alpha-\mathrm{GaPO}_{4}$ and $\alpha-\mathrm{GeO}_{2}$ piezoelectric crystals. When possible, the results are compared and discussed in the view of hydrothermally-grown $\alpha$-quartz-like $\mathrm{SiO}_{2}, \mathrm{GeO}_{2}$ and $\mathrm{GaPO}_{4}$.

\section{Flux-Growth and Morphology}

\subsection{Flux-Grown $\alpha-\mathrm{GaPO}_{4}$}

In high temperature solution growths, $\mathrm{GaPO}_{4}$ presents direct solubility. Non-toxic sodium chloride with its melting point at $800{ }^{\circ} \mathrm{C}$, is a suitable solvent to grow $\alpha-\mathrm{GaPO}_{4}$ single crystals under the temperature of the allotropic $\alpha$-quartz to $\beta$-cristobalite phase transition [75]. A graphite crucible, filled with an appropriate mixture of $\mathrm{GaPO}_{4}$ and $\mathrm{NaCl}$ was sealed in a silica ampoule under Argon. By cooling from 900 to $600{ }^{\circ} \mathrm{C}$ and pulling down the ampoule $\left(12 \mathrm{~mm} \cdot \mathrm{day}^{-1}\right)$ within a temperature gradient $\left(2-5{ }^{\circ} \mathrm{C} \cdot \mathrm{cm}^{-1}\right)$ or by using the gradient freeze method, $\alpha-\mathrm{GaPO}_{4}$ crystals having $\mathrm{NaCl}$ "foreign" phase as shown by X-ray powder diffraction diagrams were obtained. Thus, the accelerated crucible rotation technique was applied and relatively clear and unshaped $\alpha-\mathrm{GaPO}_{4}$ crystals containing flux inclusions were grown up to $5 \times 5 \times 2 \mathrm{~mm}^{3}$ in size with a rough surface.

From spontaneous crystallization with the slow cooling method $\left(1.2-5{ }^{\circ} \mathrm{C} \cdot \mathrm{h}^{-1}\right)$ between 950 and $600{ }^{\circ} \mathrm{C}$, colorless, transparent and flux inclusion-free as-grown $\alpha-\mathrm{GaPO}_{4}$ crystals of millimeter-size have been obtained in $\mathrm{MoO}_{3}$-based solvents $\mathrm{X}_{2} \mathrm{O}: 3 \mathrm{MoO}_{3}(\mathrm{X}=\mathrm{Li}, \mathrm{K})$ [44,87-89]. The melting point of these molybdenum-based solvents are between 500 and $600{ }^{\circ} \mathrm{C}$ which allows $\alpha-\mathrm{GaPO}_{4}$ growth under the allotropic phase transition temperature $[44,89]$. The unseeded growth experiments were done under atmospheric conditions in Pt crucibles covered (but not sealed) with a lid containing a starting mixture 
of $\alpha-\mathrm{GaPO}_{4}$ and $\mathrm{X}_{2} \mathrm{O}: 3 \mathrm{MoO}_{3}(\mathrm{X}=\mathrm{Li}, \mathrm{K})$ powder in different weight ratios. Plate-like single crystals with very smooth surface roughness were grown in $\mathrm{K}_{2} \mathrm{O}: 3 \mathrm{MoO}_{3}$ having a volume up to $6 \times 4 \times 1 \mathrm{~mm}^{3}$. With $\mathrm{Li}_{2} \mathrm{O}: 3 \mathrm{MoO}_{3}$ flux, the as-grown $\alpha-\mathrm{GaPO}_{4}$ crystals presented unshaped bulk morphology with a quite rough surface and volume up to $5 \times 2.5 \times 2 \mathrm{~mm}^{3}[44,87,89]$.

With a slow cooling rate of $0.1{ }^{\circ} \mathrm{C} \cdot \mathrm{h}^{-1}$ from 950 to $750{ }^{\circ} \mathrm{C}$, followed by a cooling rate of $2{ }^{\circ} \mathrm{C} \cdot \mathrm{h}^{-1}$ from 750 to $600{ }^{\circ} \mathrm{C}$, in $\mathrm{Li}_{2} \mathrm{O}: 3 \mathrm{MoO}_{3}$ flux, a visually high quality crystal of $8 \mathrm{~mm}$ long to $3 \mathrm{~mm}$ large and $2.5 \mathrm{~mm}$ thick $\left(V=60 \mathrm{~mm}^{3}\right)$ presenting two smooth major faces was grown $[89,90]$.

All these $\mathrm{X}_{2} \mathrm{O}: 3 \mathrm{MoO}_{3}$ flux-grown $\alpha-\mathrm{GaPO}_{4}$ materials crystallized in the trigonal system without any secondary phase detectable and with lattice parameters in perfect agreement with those published on hydrothermally-grown $\alpha-\mathrm{GaPO}_{4}$ material $[7,9]$.

\subsection{Flux-Grown $\alpha-G e O_{2}$}

The first attempt at growing an $\alpha-\mathrm{GeO}_{2}$ crystal by the unseeded fluxed melt method was undertaken by Finch et al. [91] in the late sixties. Among many compounds explored as potential solvents, $\mathrm{Li}_{2} \mathrm{O}: 2 \mathrm{MoO}_{3}$ and $\mathrm{Li}_{2} \mathrm{O}: 2 \mathrm{WO}_{3}$ were selected. With the slow cooling growth technique from 1100 to $950{ }^{\circ} \mathrm{C}$ at $1{ }^{\circ} \mathrm{C} \cdot \mathrm{h}^{-1}$ or less, colorless and well developed $\alpha-\mathrm{GeO}_{2}$ crystals were grown up to $3 \mathrm{~mm}$ on the edge. Crystals from $\mathrm{Li}_{2} \mathrm{O}: 2 \mathrm{MoO}_{3}$ contained impurities or defects. X-ray powder diffraction diagrams were consistent with the hexagonal modification of $\mathrm{GeO}_{2}$. In the majority, crystals were predominantly bonded by $\{10 \overline{1} 1\}$ rhombohedral faces with $\{10 \overline{1} 0\}$ prism faces incompletely developed.

In the seventies using the top seeded solution growth (TSSG) method with $\mathrm{Li}_{2} \mathrm{O}: \mathrm{WO}_{3}$ as flux, a colorless $\alpha-\mathrm{GeO}_{2}$ single-crystal with a maximum final diameter of $5 \mathrm{~mm}$ was obtained [92]. The as-grown crystal, which did not present the hexagonal-like morphology, was not sharply facetted and homogeneously transparent (white inclusions). The experimental procedure was quite unclear and some important parameters were missing. Concerning the chemical and structural quality of this TSSG-crystal, little information was given.

Recently, unseeded slow cooling growth experiments were performed from 970 to $600{ }^{\circ} \mathrm{C}$ at a cooling rate of $1{ }^{\circ} \mathrm{C} \cdot \mathrm{h}^{-1}$ with a solute to flux ratio of $10 / 90$ by weight in a Pt covered crucible (not sealed) [93,94]. Using $\mathrm{K}_{2} \mathrm{~W}_{2} \mathrm{O}_{7}$ flux, the majority of the as-grown $\alpha-\mathrm{GeO}_{2}$ crystals contained yellow flux inclusions. Thus, other inorganic solvents were investigated in the $\mathrm{MoO}_{3}$-based systems since they present low melting temperature and low evaporation at high temperatures (loss of mass $<1 \%$ after two weeks at $T>700{ }^{\circ} \mathrm{C}$ for $\mathrm{K}_{2} \mathrm{Mo}_{4} \mathrm{O}_{13}$ flux) $[93,94]$. Well-faceted and visually colorless and transparent $\alpha-\mathrm{GeO}_{2}$ single-crystals were obtained in fluxes such as $\mathrm{K}_{2} \mathrm{Mo}_{4} \mathrm{O}_{13}, \mathrm{Rb}_{2} \mathrm{Mo}_{4} \mathrm{O}_{13}$ and $\mathrm{Rb}_{2} \mathrm{Mo}_{2} \mathrm{O}_{7}$. The as-grown crystals had no visible flux inclusions, bubbles or cracks and presented very smooth surface roughness $[16,93,94]$. The $\alpha-\mathrm{GeO}_{2}$ millimeter-size crystals, up to $3 \mathrm{~mm}$, presented either an unshaped morphology or a pseudo-cubic shape as already found for natural $\alpha$-quartz [95]. In the case of pseudo-cubic crystals, the positive $r\{10 \overline{1} 1\}$ rhombohedral faces were prevalent with the restricted presence of the negative $z\{01 \overline{1} 1\}$ rhombohedral faces while $m\{10 \overline{1} 0\}$ faces were absent [93,94].

The crystal structure and quality of these flux-grown $\alpha-\mathrm{GeO}_{2}$ materials were studied by both powder and single-crystal X-ray diffraction at room temperature $[16,93,94]$. The refinements confirmed the crystallization of the $\alpha$-quartz-type structure and the lattice parameters and volumes were in good agreement with the literature data $[4,10,11,32,80]$. The excellent final reliability factors of the 
refinements indicated that the as-grown $\alpha-\mathrm{GeO}_{2}$ crystals were of high quality precluding the presence of any considerable amount of twinning [16]. The value of the Flack coefficient which is an indicator of the presence of growth portions containing mirror-image was found close to zero. The uniform coloration of the natural faces under polarized light indicated the lack of optical domains in the flux-grown $\alpha-\mathrm{GeO}_{2}$ single crystals [16,93].

A colorless, well facetted, highly-transparent and large-size single crystal, up to $0.5 \mathrm{~cm}^{3}$, of the piezoelectric phase of $\mathrm{GeO}_{2}$ was grown by TSSG from a high temperature solution using $\mathrm{K}_{2} \mathrm{Mo}_{4} \mathrm{O}_{13}$ as solvent [27,93]. The obtained volume made this isometric flux-grown $\mathrm{GeO}_{2}$ single crystal, Figure 1, with the metastable $\alpha$-quartz like structure, the largest reported in the literature. The macroscopic hexagonal morphology, similar to the well-known morphology of $\alpha-\mathrm{SiO}_{2}$, was in accordance with an $\alpha$-quartz-like structure and facilitated the identification of the different natural crystallographic faces [96-98].

Figure 1. Picture of an $\alpha-\mathrm{GeO}_{2}$ single crystal grown by the top seeded solution growth (TSSG) technique in $\mathrm{K}_{2} \mathrm{Mo}_{4} \mathrm{O}_{13}$ flux.

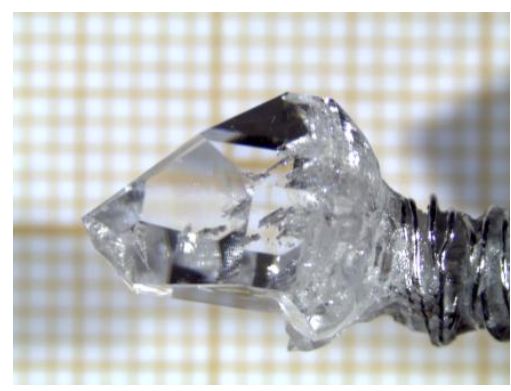

\section{Impurities Contamination}

\subsection{Flux-Grown $\alpha-\mathrm{GaPO}_{4}$}

The $\mathrm{OH}$ contamination of the crystalline lattice during crystallization via growth medium, which decreases the Q-factor of the resonators, has been largely reported in the literature concerning $\alpha-\mathrm{GaPO}_{4}$ grown by the hydrothermal method $[43,52,53,55,57,68,71,99,100]$.

The visual estimation of the $\mathrm{OH}$ contamination of the $\alpha-\mathrm{GaPO}_{4}$ single crystals flux-grown from $\mathrm{NaCl}$ solvent was studied by annealing experiments [75]. The "milky" clouding was a direct estimation of the $\mathrm{OH}^{-}$concentration; the higher the $\mathrm{OH}$ content, the more "milky" is the sample. These $\mathrm{NaCl}$ flux-grown $\alpha-\mathrm{GaPO}_{4}$ crystals presented slight clouding and thus significant $\mathrm{OH}$ contamination.

In a typical room temperature non-polarized infrared transmission spectrum of an $\alpha-\mathrm{GaPO}_{4}$ material containing significant $\mathrm{OH}$-groups, a broad and intense band between 2500 and $3600 \mathrm{~cm}^{-1}$ is observed (O-H infrared region) associated with $\mathrm{H}$-bonded molecular water. This broad band is superimposed upon three well-separated peaks at 3167,3290 and $3400 \mathrm{~cm}^{-1}$ and sometimes upon a sharp absorption band at $3508 \mathrm{~cm}^{-1}$ related to an isolated $\mathrm{OH}$-group stretching band $[43,55,65,68]$. The amplitude of the peak centered around $3400 \mathrm{~cm}^{-1}$ is attributed in one part to the absorption by the $\mathrm{GaPO}_{4}$ lattice and in another part to $\mathrm{O}-\mathrm{H}$ stretching vibrations [65].

For $\mathrm{X}_{2} \mathrm{O}: 3 \mathrm{MoO}_{3}(\mathrm{X}=\mathrm{Li}, \mathrm{K})$ flux-grown $\alpha-\mathrm{GaPO}_{4}$ materials, the collection of the non-polarized infrared data was done in transmission mode at room temperature on as-grown samples, i.e., not 
polished samples. Only the three bands at 3167,3290 and $3400 \mathrm{~cm}^{-1}$ were registered. The OH content was materials $[44,46,88-90,101]$. Compared to the spectra of hydrothermally-grown $\mathrm{GaPO}_{4}$, they did not present the characteristic broad and intense absorption band from 3600 to $2500 \mathrm{~cm}^{-1}$ due to quite strong $\mathrm{OH}$ contamination estimated with the extinction coefficient $\alpha$ calculated at $3400 \mathrm{~cm}^{-1}$ from the expression $\alpha=1 / d\left[\log \left(T_{3800} / T_{3400}\right)\right]-\alpha_{3400} *$ where $d$ represents the sample thickness in $\mathrm{cm}, T$ represents the \% IR transmission at respectively 3800 and $3400 \mathrm{~cm}^{-1}$, and $\alpha_{3400} *$ represents the absorption coefficient due to intrinsic lattice vibrations of $\alpha-\mathrm{GaPO}_{4}$ at $3400 \mathrm{~cm}^{-1}$ [65]. The $\alpha_{3400} *$ was estimated to be $0.078 \mathrm{~cm}^{-1}$ based on hydrothermally-grown material $[65,68,102]$.

The calculated value of the extinction coefficient $\alpha$ at $3400 \mathrm{~cm}^{-1}$ was close to $0.03 \mathrm{~cm}^{-1}$ for $\mathrm{X}_{2} \mathrm{O}: 3 \mathrm{MoO}_{3}(\mathrm{X}=\mathrm{Li}, \mathrm{K})$ flux-grown $\mathrm{GaPO}_{4}$ and close to $0.15 \mathrm{~cm}^{-1}$ for hydrothermally-grown material [88]. Thus, the infrared spectra correspond to $\mathrm{X}_{2} \mathrm{O}: 3 \mathrm{MoO}_{3}(\mathrm{X}=\mathrm{Li}, \mathrm{K})$ flux-grown $\alpha-\mathrm{GaPO}_{4}$ samples without significant $\mathrm{OH}$-content in perfect accordance with the absence of "milky" clouding of the samples even after several times heating up to $850{ }^{\circ} \mathrm{C}$ [103].

Chemical analyses of $\mathrm{X}_{2} \mathrm{O}: 3 \mathrm{MoO}_{3}(\mathrm{X}=\mathrm{Li}, \mathrm{K})$ flux-grown $\alpha-\mathrm{GaPO}_{4}$ crystals were done using glow discharge mass spectrometry (GDMS) and induced coupled plasma-atomic emission spectroscopy (ICP-AES) [89]. The results demonstrated the presence of foreign chemical elements coming from the solvent with a Mo-content as high as $0.3 \%$ for $\mathrm{GaPO}_{4}$ crystals grown in $\mathrm{K}_{2} \mathrm{O}: 3 \mathrm{MoO}_{3}$ flux. $\mathrm{Na}, \mathrm{Ca}, \mathrm{Fe}$, $\mathrm{Al}$ and $\mathrm{Si}$ elements were also found with a major contamination from $\mathrm{Al}$ element ( $320 \mathrm{ppm}$ to $0.13 \%$ ).

\subsection{Flux-Grown $\alpha-G e \mathrm{O}_{2}$}

As for hydrothermally-grown $\alpha-\mathrm{GaPO}_{4}$ single crystals, $\mathrm{OH}$ contamination of the lattice was reported for hydrothermally-grown $\alpha-\mathrm{GeO}_{2}[43,79,80,94]$. In a non-polarized infrared spectrum collected in the transmission mode of a hydrothermally-grown $\alpha-\mathrm{GeO}_{2}$ material containing significant OH-groups, Figure 2, a well-pronounced broad band between 2500 and $3800 \mathrm{~cm}^{-1}$ is observed with maxima at about 3455,3500 and $3562 \mathrm{~cm}^{-1}$ attributed to $\mathrm{Ge}-\mathrm{OH}$ vibration groups [43,79,81,94]. For both spontaneously nucleated $\mathrm{MoO}_{3}$-based flux-grown $\alpha-\mathrm{GeO}_{2}$ samples and TSSG-grown $\alpha-\mathrm{GeO}_{2}$ oriented plates of simple crystallographic orientations, infrared spectra characterize $\mathrm{OH}$-free flux-grown $\alpha-\mathrm{GeO}_{2}$ crystals [27,93] as evidenced by the absence of both a broad band and sharp peaks in the $2800-3500 \mathrm{~cm}^{-1}$ range, Figure 2.

Room temperature non-polarized Raman spectra of commercial $\alpha-\mathrm{GeO}_{2}$ powder or $\alpha-\mathrm{GeO}_{2}$ stain-etch sample exhibited some features around 760-780 $\mathrm{cm}^{-1}$ which were found to disappear once the sample was annealed in air above $400{ }^{\circ} \mathrm{C}$ [39,93,104-106]. These features have been assigned either to oxygen vacancy complexes or to water bound to $\mathrm{Ge}-\mathrm{O}$ entities or to a $\mathrm{Ge}-\mathrm{O}$ stretching vibration of a water-distorted $\mathrm{GeO}_{4}$ entity [39,104,105].

The non-polarized Raman signal of a $\mathrm{MoO}_{3}$-based flux-grown $\alpha$-quartz $\mathrm{GeO}_{2}$ single crystal was collected in the $50-4000 \mathrm{~cm}^{-1}$ range and no other modes than the four non-degenerate A1 ones and the eight doubly-degenerate $\mathrm{E}$ modes predicted by group theory for $\alpha$-quartz-type $\mathrm{GeO}_{2}\left(\mathrm{D}_{3}\right.$ point group) were observed [93,106-108]. In agreement with infrared measurements [27,93], neither hydroxyl groups nor water inclusions were detected by Raman spectroscopy. Furthermore, these $\mathrm{MoO}_{3}$-based flux-grown $\alpha-\mathrm{GeO}_{2}$ samples were heated up to $1000{ }^{\circ} \mathrm{C}$ several times without presenting the well-known milky hue attributed to the release of water from hydroxyl impurities with increasing temperature [109]. 
Figure 2. Infrared transmission spectra of flux- and hydrothermally-grown $\alpha-\mathrm{GeO}_{2}$ single crystals.

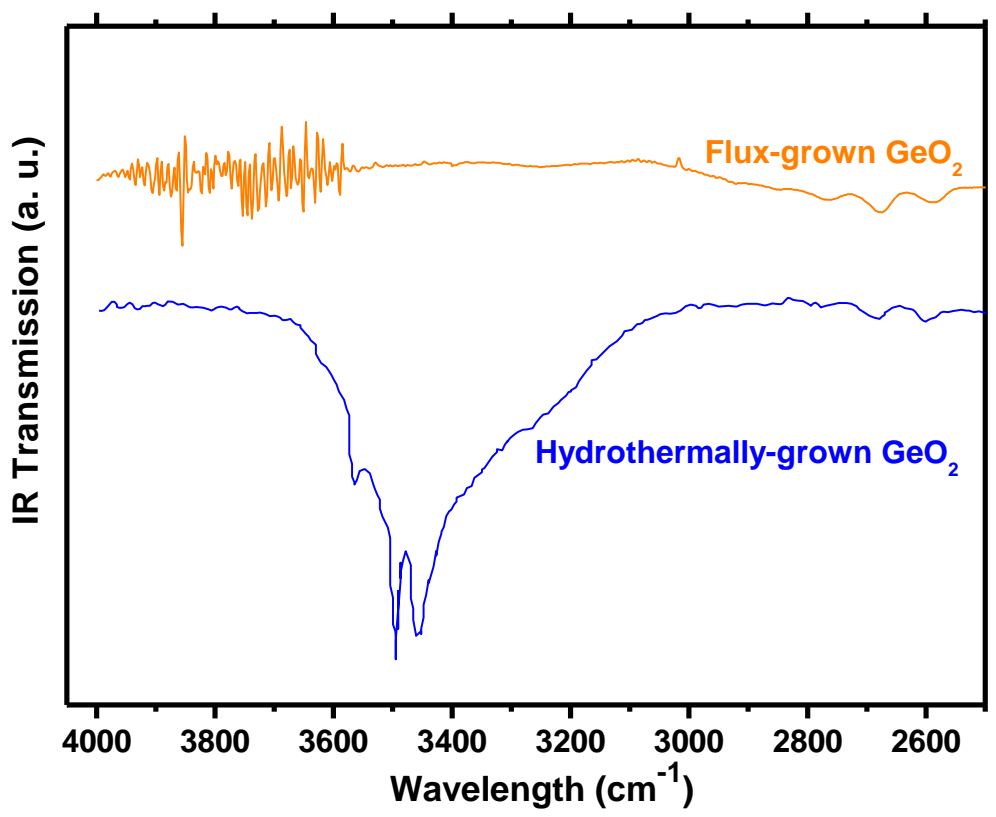

Ambient polarized Raman measurements performed on flux-grown $\alpha$-quartz $\mathrm{GeO}_{2}$ single crystals along with state of the art density functional theory (DFT) based calculations were reported [93,106,107]. An excellent agreement was obtained between experimental and theoretical Raman lines for both wavenumbers and relative intensities which permitted to unambiguously assign the symmetry and the nature of $\alpha$-quartz $\mathrm{GeO}_{2}$ modes. This Raman study pointed out that high temperature flux-grown $\mathrm{GeO}_{2}$ single crystals of $\alpha$-quartz-like structure were of high structural quality (impurities would have resulted in shifts of the Raman lines or in additional bands), and that vibrations in the $\alpha$-quartz $\mathrm{GeO}_{2}$ structure were relatively quasi-harmonic as the calculated frequencies at $-273{ }^{\circ} \mathrm{C}$ were almost the same as the experimental values at $25^{\circ} \mathrm{C}$.

Optical transmittance was measured in the UV-VIS-NIR region for a plate with a surface perpendicular to the $c$ axis prepared from a $\mathrm{MoO}_{3}$-based TSSG-grown $\alpha-\mathrm{GeO}_{2}$ single crystal [27]. The transmission spectrum was taken on an as-grown crystal plate of $330 \mu \mathrm{m}$ in thickness. The transmission fraction, found to be over $97 \%$ in the VIS-NIR region, showed that the TSSG-grown $\alpha-\mathrm{GeO}_{2}$ crystal was of very good optical quality. The high chemical purity and the homogeneity of the TSSG-GeO${ }_{2}$ crystal were also revealed by the absence of absorption bands. The $\alpha-\mathrm{GeO}_{2}$ crystal exhibited transparency down to the UV region. Below $300 \mathrm{~nm}$, a strong absorption was visible due to the fundamental absorption within the band gap with a cutoff at $205 \mathrm{~nm}$.

Optical transmission was reported for hydrothermally-grown $\alpha-\mathrm{GeO}_{2}$ crystal [79]. The spectrum showed a considerable absorption in the $0.20-0.210 \mu \mathrm{m}$ range associated with the presence of several bands [79]. 


\section{Thermal Characterizations}

\subsection{Flux-Grown $\alpha-\mathrm{GaPO}_{4}$}

Differential scanning calorimetric (DSC) experiments were done on flux-grown $\alpha-\mathrm{GaPO}_{4}$ single crystals crystallized via spontaneous nucleation in $\mathrm{MoO}_{3}$-based fluxes as $\mathrm{Li}_{2} \mathrm{O}: 3 \mathrm{MoO}_{3}$ and $\mathrm{K}_{2} \mathrm{O}: 3 \mathrm{MoO}_{3}[44,46,89,90,101]$. On heating runs up to $1200{ }^{\circ} \mathrm{C}\left(2-10{ }^{\circ} \mathrm{C} \cdot \mathrm{min}^{-1}\right)$ of $\alpha-\mathrm{GaPO}_{4}$ as-grown single crystals or powdered samples, only a sharp endothermic peak appeared in the 950-964 ${ }^{\circ} \mathrm{C}$ temperature range, Figure 3, caused by the structural transition from the $\alpha$-quartz $\mathrm{GaPO}_{4}$ phase to the $\beta$-cristobalite modification stable above $960-980{ }^{\circ} \mathrm{C}$ [40-42].

Figure 3. Differential scanning calorimetric (DSC) curves of powdered flux-grown $\alpha-\mathrm{GaPO}_{4}$ crystals registered with a thermal cycle of $2{ }^{\circ} \mathrm{C} / \mathrm{min}$.

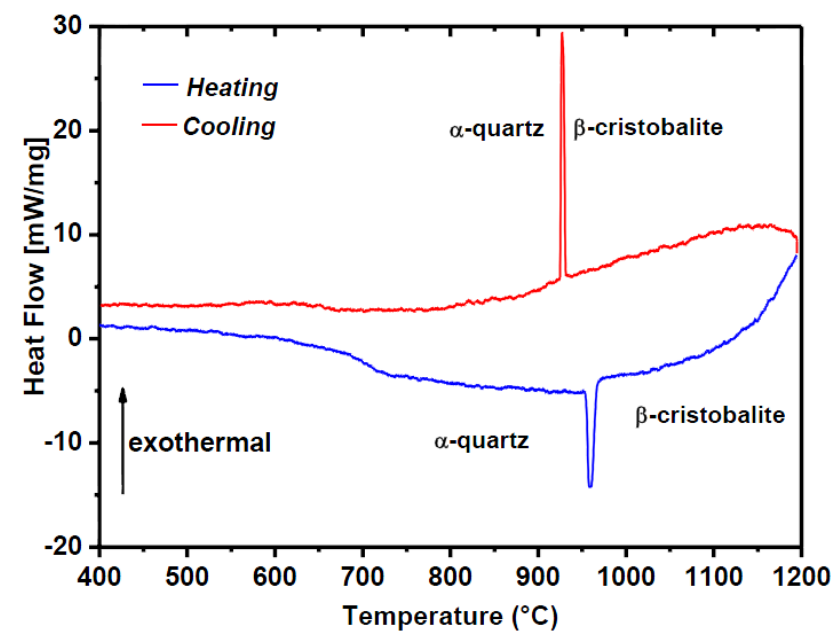

The successive cooling $\left(-5^{\circ} \mathrm{C} / \mathrm{min}\right)$ data registered from $1200{ }^{\circ} \mathrm{C}$ back to room temperature of a sample containing some as-grown single crystals (different sizes and faces) presented a unique exothermic feature with double maxima at onset temperature of $937{ }^{\circ} \mathrm{C}$ for the first thermal cycle, and at onset temperature of $925^{\circ} \mathrm{C}$ in the second cycle [101].

When the as-grown $\alpha-\mathrm{GaPO}_{4}$ crystals were powdered and sieved to a regular grain size $(20 \mu \mathrm{m})$, the successive cooling $\left(-2\right.$ or $-10{ }^{\circ} \mathrm{C} / \mathrm{min}$ ) curves, from 1200 to $20^{\circ} \mathrm{C}$, showed only one exothermic peak in the $942-908^{\circ} \mathrm{C}$ temperature range depending on the flux composition, Figure 3.

This exothermic feature corresponded to a total transformation of the $\beta$-cristobalite $\mathrm{GaPO}_{4}$ phase into the $\alpha$-quartz phase as confirmed by the X-ray powder pattern of the end product of the DSC analysis $[44,46,89,90]$. This was the first time that $\mathrm{GaPO}_{4}$ had been found, after a DSC cycle, exclusively in the $\alpha$-quartz modification after cooling from the $\beta$-cristobalite phase without annealing periods.

Effectively, concerning the hydrothermally-grown $\alpha-\mathrm{GaPO}_{4}$ material grown at $300{ }^{\circ} \mathrm{C}$ (direct solubility), the successive cooling curve $\left(-10{ }^{\circ} \mathrm{C} / \mathrm{min}\right)$ from $1200{ }^{\circ} \mathrm{C}$ back to $20{ }^{\circ} \mathrm{C}$, showed two main exothermic peaks [43,90]: one with an onset temperature of $910{ }^{\circ} \mathrm{C}$ due to a partial transformation of the $\beta$-cristobalite $\mathrm{GaPO}_{4}$ phase in $\alpha$-quartz phase and a second, close to $578{ }^{\circ} \mathrm{C}$, attributed to the $\beta$-cristobalite/ $\alpha$-cristobalite transition [40-42]. 
For hydrothermally-grown $\alpha-\mathrm{GaPO}_{4}$ material grown at $230{ }^{\circ} \mathrm{C}$ (indirect solubility), only one strong exothermic peak was visible on the cooling curve close to $578^{\circ} \mathrm{C}$ corresponding to a total transformation of the $\beta$-cristobalite to $\alpha$-cristobalite [43]. The crystallization temperature of the $\alpha-\mathrm{GaPO}_{4}$ phase would be an important parameter to favor the reversible $\alpha$-quartz/ $\beta$-cristobalite transition.

The thermal evolution of flux-grown $\alpha-\mathrm{GaPO}_{4}$ single crystals grown from 950 to $600{ }^{\circ} \mathrm{C}$ in $\mathrm{MoO}_{3}$-based solvents was also followed by Raman spectroscopy [45]. A direct $\alpha$-quartz/ $\beta$-cristobalite transition was observed at a temperature close to $980{ }^{\circ} \mathrm{C}$ upon heating. Back transformation to the $\alpha$-quartz-type form was found to occur readily at $920{ }^{\circ} \mathrm{C}$ in perfect agreement with the DSC experiments $[44,46,89,90,101]$.

The temperature dependence of the cell parameters of a $\alpha-\mathrm{GaPO}_{4}$ sample grown in a $\mathrm{Li}_{2} \mathrm{O}-3 \mathrm{MoO}_{3}$ flux over the temperature range $950-600{ }^{\circ} \mathrm{C}$ was determined from powder X-ray diffraction data collected from 30 to $900{ }^{\circ} \mathrm{C}$ [103]. The X-ray patterns remained the same from room temperature to $900{ }^{\circ} \mathrm{C}$. Both the lattice parameters and unit cell volumes were found to increase markedly and nonlinearly (third degree polynomial) as a function of temperature. Therefore, no indication of a structural transition was pointed out in the studied temperature range $\left(30-900{ }^{\circ} \mathrm{C}\right)$ in perfect agreement with previous reported results obtained from DSC [44,46,89,90,101] or Raman studies [45,89] concerning $\mathrm{MoO}_{3}$-based flux-grown $\alpha$ - $\mathrm{GaPO}_{4}$ crystals.

\subsection{Flux-Grown $\alpha-\mathrm{GeO}_{2}$}

In the temperature range from room temperature to $1200{ }^{\circ} \mathrm{C}$, the $\mathrm{DSC}$ heating-curve of $\mathrm{GeO}_{2}$ crystals with the $\alpha$-quartz structure grown by the spontaneous nucleation method in selected fluxes ( $\mathrm{MoO}_{3}$-based compounds) showed no other peak than an endothermic feature attributed to the melting of the studied material at maximum of $1116{ }^{\circ} \mathrm{C}[93,94]$.

Powder X-ray patterns of flux-grown $\alpha-\mathrm{GeO}_{2}$ were registered at several temperatures from room temperature up to $1050{ }^{\circ} \mathrm{C}[93,109]$. For each studied temperature, the whole diffraction pattern was assigned to the $\alpha$-quartz phase of $\mathrm{GeO}_{2}$. The very interesting results brought to light by these thermal analyses were that this high temperature flux-grown oxide material did not present a phase transition before melting (unlike $\mathrm{SiO}_{2}$ with the well-known $\alpha$-quartz/ $\beta$-quartz transformation close to $\left.573{ }^{\circ} \mathrm{C}[19,28]\right)$ and that no secondary phases such as the $\mathrm{GeO}_{2}$ rutile-like phase or flux-derived phases were detected.

Variable-temperature Raman spectroscopy measurements performed on high temperature flux-grown $\alpha$-quartz $\mathrm{GeO}_{2}$ single crystals in $\mathrm{MoO}_{3}$-based solvents were reported [93,106]. Vibrations in $\alpha-\mathrm{GeO}_{2}$ were shown to be very slightly anharmonic as evidenced by the very low wavenumber shifts and the weak damping of the modes between room temperature and $1100{ }^{\circ} \mathrm{C}$. In contrast with what has been observed for other $\alpha$-quartz homeotypes like $\mathrm{SiO}_{2}$ or $\mathrm{AlPO}_{4}$, which undergo an $\alpha$-quartz to $\beta$-quartz phase transition $[19,28]$, neither phase transitions nor a second phase were detected by this Raman study from room temperature to $1100{ }^{\circ} \mathrm{C}$. First-principle calculations with the ABINIT code $[93,106,107]$ revealed the absence of the tetrahedral libration mode in the $\alpha$-quartz-like structure of $\mathrm{GeO}_{2}$ which explained the very low degree of thermally-induced dynamic disorder registered in the $30-1100{ }^{\circ} \mathrm{C}$ range and further confirmed that the piezoelectric properties of flux-grown $\alpha-\mathrm{GeO}_{2}$ should not be degraded significantly up to its melting point $\left(1116^{\circ} \mathrm{C}\right)$. 
To confirm the thermal stability (aging), an as-grown $\alpha-\mathrm{GeO}_{2}$ single crystal obtained by spontaneous nucleation in $\mathrm{MoO}_{3}$-based flux was annealed in air at high temperature (800-900 ${ }^{\circ} \mathrm{C}$ ) over several months [27]. The impact of this thermal cycle on the $\alpha$-quartz-like structure of $\mathrm{GeO}_{2}$ was followed by Raman measurement. This long annealing process validated the excellent aging behavior under very high thermal stress of the $\alpha$-quartz $\mathrm{GeO}_{2}$ obtained from the flux method since no phase transition and no evolution of the visual transparency were detected. This important result could be directly related to the high crystalline quality of the $\alpha-\mathrm{GeO}_{2}$ single crystals accessible with the flux growth techniques (water-free, chemical inclusion-free and rutile phase-free) as illustrated by the optical transmission curve [27].

\section{Elastic Constants}

\subsection{Ambient Conditions}

Using Voigt's notation and taking into account the crystal symmetry, the $\alpha$-quartz structure (point group 32) presents six independent elastic stiffness moduli $C_{I J}$ ( $I, J$ indices from 1 to 6): $C_{11}, C_{33}, C_{44}$, $C_{66}, C_{12}, C_{13}$ and $C_{14}\left(2 C_{66}=C_{11}-C_{12}\right)$. To identify the crystalline orientation, $\alpha$-quartz analogues use a standard Cartesian coordinate system where the $Z$-axis of $\alpha$-quartz analogues coincides with the crystallographic $c$-axis; the $X$-axis matches the crystallographic $a$-axis and the $Y$-axis is normal to the $X$ and $Z$ axes ( $b$-axis being in the $X Y$ plane at $120^{\circ}$ from $a$-axis).

\subsubsection{Flux-Grown $\alpha-\mathrm{GaPO}_{4}$}

By the ultrasonic method, a determination of four out of six independent single-crystal elastic stiffness constants $C^{\mathrm{E}}{ }_{I J}$ at constant electric field was undertaken on millimeter suitable shaped plates obtained from as-grown $\alpha-\mathrm{GaPO}_{4}$ single crystals spontaneously crystallized by slowly cooling a $\mathrm{Li}_{2} \mathrm{O}: 3 \mathrm{MoO}_{3}$ flux saturated with $\mathrm{GaPO}_{4}[46,89,110]$. The average size of the $\mathrm{MoO}_{3}$-based flux-grown $\mathrm{GaPO}_{4}$ single crystals was too small $[44,46,89,90,101]$ to get all the orientations useful for the measurements of the whole elastic constant set (ex: $C^{\mathrm{E}}{ }_{13}$ ).

Single-crystal high-resolution Brillouin spectroscopy experiments were carried out to measure five out of six $\left(C^{\mathrm{E}}{ }_{13}\right.$ is missing) elastic constants $C^{\mathrm{E}}{ }_{I J}$ of flux-grown $\alpha-\mathrm{GaPO}_{4}$ material $[90,103]$. Optical quality single-crystals of $\alpha-\mathrm{GaPO}_{4}$ with millimeter size were flux-grown from $\mathrm{X}_{2} \mathrm{O}: 3 \mathrm{MoO}_{3}(\mathrm{X}=\mathrm{Li}, \mathrm{K})$ solvent in unseeded experiments over the $950-600{ }^{\circ} \mathrm{C}$ temperature range. The Brillouin measurements were done, on one hand, on plates of simple $X$-, $Y$ - and Z-orientation [90] and on other hand, on an as-grown $\alpha-\mathrm{GaPO}_{4}$ single crystal polished as a cube with $2 \mathrm{~mm}$ side length showing $X(100), Y(010)$ and $Z$ (001) faces [103].

Table 1 gives the resulting single crystal elastic stiffness constants $C_{I J}^{\mathrm{E}}$ obtained on high temperature flux-grown $\alpha-\mathrm{GaPO}_{4}$ materials in $\mathrm{MoO}_{3}$-based solvents. They are compared with a reported experimental set of data concerning the hydrothermally-grown $\mathrm{GaPO}_{4}$ single crystals as well as with reported computed values [111].

The values of the flux-grown single crystal elastic stiffness constants $C^{\mathrm{E}}{ }_{I J}$ compared with those obtained by Brillouin or pulse-echo methods on hydrothermally-grown samples, Table 1, are in good accordance while large discrepancies exist with the computed values concerning $C^{\mathrm{E}}{ }_{11}$ and $C^{\mathrm{E}}{ }_{66}$. 
Table 1. Computed and experimental elastic stiffness constants $C^{\mathrm{E}}{ }_{I J}[\mathrm{GPa}]$ of $\alpha-\mathrm{GaPO}_{4}$.

\begin{tabular}{|c|c|c|c|}
\hline Elastic constant & Hydrothermal-Growth & Computed values $\left(-273^{\circ} \mathrm{C}\right)$ & Flux-Growth \\
\hline$C^{\mathrm{E}}{ }_{11}$ & $\begin{array}{c}66.58[112] \\
66.35[67] \\
66.60[17] \\
66.58[113]\end{array}$ & $79.80[111]$ & $\begin{array}{c}64.01[46,110] \\
66.37[90] \\
66.52[103]\end{array}$ \\
\hline$\left[=\left(C_{11}^{\mathrm{E}}-2 C_{66}^{\mathrm{E}}\right)\right]$ & $\begin{array}{c}21.81[112] \\
21.65[67] \\
21.80[17] \\
17.38[113] \\
\end{array}$ & $16.60[111]$ & $\begin{array}{c}13.51[46,110] \\
21.45[90] \\
21.04[103]\end{array}$ \\
\hline$\left|C^{\mathrm{E}}{ }_{14}\right|$ & $\begin{array}{c}3.91[112] \\
4.20[67] \\
3.90[17] \\
5.14[113] \\
\end{array}$ & 3.20 [111] & $\begin{array}{c}5.52[46,110] \\
4.93[90] \\
5.53[103]\end{array}$ \\
\hline$C_{33}^{\mathrm{E}}$ & $\begin{array}{c}102.13[112] \\
101.31[67] \\
102.10[17] \\
102.13[113] \\
\end{array}$ & $106.30[111]$ & $\begin{array}{c}103.29[90] \\
103.88[103]\end{array}$ \\
\hline$C_{44}^{\mathrm{E}}$ & $\begin{array}{c}37.66[112] \\
37.80[67] \\
37.70[17] \\
39.68[113] \\
\end{array}$ & $39.90[111]$ & $\begin{array}{c}39.39[46,110] \\
37.85[90] \\
38.01[103]\end{array}$ \\
\hline$C_{66}^{\mathrm{E}}$ & $\begin{array}{l}22.38[112] \\
22.35[67] \\
22.40[17] \\
24.60[113]\end{array}$ & $31.60[111]$ & $\begin{array}{c}21.25[46,110] \\
22.46[90] \\
22.74[103]\end{array}$ \\
\hline
\end{tabular}

\subsubsection{Flux-Grown $\alpha-\mathrm{GeO}_{2}$}

The room temperature experimental values of single-crystal elastic stiffness constants $C^{\mathrm{E}}{ }_{I J}$ at constant electric field of flux-grown $\alpha-\mathrm{GeO}_{2}$ in $\mathrm{MoO}_{3}$-based solvents were determined using Brillouin scattering, Table 2 [109]. In this work, three platelets were used, defined in the standard Cartesian coordinate system as $X$-plate, $Y$-plate and $Z$-plate which respectively correspond to the (100), (2-10) and (003) $(h k l)$-crystallographic planes.

These flux-grown $\alpha-\mathrm{GeO}_{2} C_{I J}$ values are compared in Table 2 with recent computed $[109,114,115]$ and experimental elastic constant data obtained from hydrothermally-grown crystals $[23,24,116] . C^{\mathrm{D}}{ }_{\mathrm{IJ}}$ are elastic stiffness constants at constant electric displacement i.e., not corrected from the piezoelectric effect $\mathrm{e}_{11}^{2} / \varepsilon_{11}$ where $\mathrm{e}_{11}$ is the piezoelectric stress constant and $\varepsilon_{11}$ the dielectric tensor at constant strain.

The crystal elastic constants values of the $\mathrm{MoO}_{3}$-based flux-grown $\alpha-\mathrm{GeO}_{2}$ material present close similarities with most of the published $C_{I J}$ data on hydrothermally-grown $\alpha-\mathrm{GeO}_{2}$ crystals, Table 2 . Therefore, the small discrepancy, registered more especially on the $C_{11}$ and $C_{14}$ moduli, was attributed to the strong reduction of the $\mathrm{OH}$ concentration in the lattice of flux-grown $\alpha-\mathrm{GeO}_{2}$ crystals which was believed to induce a slightly stiffer behavior [109]. The presence of $\mathrm{OH}$-interactions in the crystal would increase its ionic character and consequently softer its elastic behavior. 
When compared with calculated elastic stiffness constants, the flux-grown $\alpha-\mathrm{GeO}_{2}$ elastic moduli presented very good agreement with computed values at $0 \mathrm{~K}$ of Lignie et al. [109], Table 2. The largest discrepancy was observed for the $C_{66}$ (nearly $13 \%$ softer for the theoretical value) while very good accordance was found for the $C_{12}$ and $C_{14}$ elastic constants.

The numerical value of the $\mathrm{e}_{11}^{2} / \varepsilon_{11}$ piezoelectric term, deduced from the $C^{\mathrm{D}}{ }_{11}$ to $C^{\mathrm{E}}{ }_{11}$ difference, Table 2, is 1.29(2) GPa [109]. The authors deduced for the flux-grown $\alpha-\mathrm{GeO}_{2}$ material a $d_{11}$ piezoelectric strain constant of $5.7(2) \times 10^{-12} \mathrm{C} / \mathrm{N}$ which is in between the calculated and the reported experimental value from a hydrothermally-grown $\alpha-\mathrm{GeO}_{2}$ crystal, Table 3.

Table 2. Computed and experimental elastic stiffness constants $C_{I J}[\mathrm{GPa}]$ of $\alpha-\mathrm{GeO}_{2}$.

\begin{tabular}{|c|c|c|c|}
\hline Elastic constant & Hydrothermal-Growth & Computed values & Flux-Growth [107] \\
\hline \multirow{4}{*}{$\begin{array}{l}C^{\mathrm{E}}{ }_{11} \\
C^{\mathrm{D}}{ }_{11}\end{array}$} & $64.00[116]$ & \multirow{4}{*}{$\begin{array}{l}62.90[109] \\
69.90[114] \\
56.15[115]\end{array}$} & \multirow{4}{*}{$\begin{array}{l}68.1(1) \\
69.3(1)\end{array}$} \\
\hline & $64.80[23]$ & & \\
\hline & $66.40[24]$ & & \\
\hline & $64.13[23]$ & & \\
\hline \multirow{3}{*}{$C^{\mathrm{E}}{ }_{12}$} & \multirow{3}{*}{$\begin{array}{c}22.00[116] \\
21.30[24]\end{array}$} & 25.50 [109] & \multirow{3}{*}{$25.1(1)$} \\
\hline & & $8.40[114]$ & \\
\hline & & $12.03[115]$ & \\
\hline \multirow{3}{*}{$C_{13}^{\mathrm{E}}$} & \multirow{3}{*}{$32.00[116]$} & $25.70[109]$ & \multirow{3}{*}{-} \\
\hline & & $4.10[114]$ & \\
\hline & & $19.39[115]$ & \\
\hline \multirow{3}{*}{$\left|C^{\mathrm{E}}{ }_{14}\right|$} & $2.00[116]$ & 0.60 [109] & \multirow{3}{*}{$\approx 0$} \\
\hline & $11.70[23]$ & $15.6[114]$ & \\
\hline & $2.20[24]$ & 0 [115] & \\
\hline \multirow{3}{*}{$C_{33}^{\mathrm{E}}$} & \multirow{3}{*}{$\begin{array}{c}118.0[116] \\
116.0[24]\end{array}$} & 116.80 [109] & \multirow{3}{*}{$118.8(2)$} \\
\hline & & $91.60[114]$ & \\
\hline & & $99.05[115]$ & \\
\hline \multirow{3}{*}{$C_{44}^{\mathrm{E}}$} & $37.00[116]$ & $35.00[109]$ & \multirow{3}{*}{$38.6(1)$} \\
\hline & $37.84[23]$ & $38.40[114]$ & \\
\hline & $26.80[24]$ & 39.99 [115] & \\
\hline \multirow{4}{*}{$\begin{array}{l}C_{66}^{\mathrm{E}} \\
C_{66}^{\mathrm{D}}\end{array}$} & $21.00[116]$ & 1870 [109] & \multirow{4}{*}{$\begin{array}{l}21.5(1) \\
22.7(1)\end{array}$} \\
\hline & $21.10[23]$ & $18.70[109]$ & \\
\hline & $22.53[24]$ & $20.10[114]$ & \\
\hline & $24.90-25.14[23]$ & $22.06[115]$ & \\
\hline
\end{tabular}

Table 3. Piezoelectric strain coefficient $d_{11}$ of $\alpha-\mathrm{GeO}_{2}$ and $\alpha-\mathrm{SiO}_{2}$ (given for comparison).

\begin{tabular}{ccccc}
\hline Material & & $\boldsymbol{\alpha}-\mathbf{G e O}_{\mathbf{2}}$ & $\boldsymbol{\alpha - S i O} \mathbf{2}$ \\
\hline $\begin{array}{c}\text { Piezoelectric } \\
\text { constant }\end{array}$ & Hydrothermal-Growth & Predicted values & Flux-Growth & Hydrothermal-Growth \\
\hline & $4.04[23]$ & $7.43[109]$ & & \\
$\boldsymbol{d}_{\mathbf{1 1}}\left(\mathbf{1 0}^{-\mathbf{1 2}} \mathbf{C} / \mathbf{N}\right)$ & $4.10[24]$ & $4.30[117]$ & $5.7(2)[109]$ & $2.31[17]$ \\
& $8.7-9.4[29]$ & $6.00[117]$ & & \\
\hline
\end{tabular}


The flux-grown $\alpha-\mathrm{GeO}_{2}$ exhibits a $d_{11}$ piezoelectric strain constant more than twice that of $\alpha$-quartz $\mathrm{SiO}_{2}$, Table 3, confirming the improvement of the piezoelectric properties with the structural distortion in the $\alpha$-quartz analogues $[17,117]$.

\subsection{High Temperature}

\subsubsection{Flux-Grown $\alpha-\mathrm{GaPO}_{4}$}

High-resolution Brillouin spectroscopy studies concerning the $C_{I J}$ elastic stiffness constant evolution with temperature of high-temperature flux-grown $\alpha-\mathrm{GaPO}_{4}$ single-crystals are reported in the literature $[90,103]$. Since for Brillouin scattering experiments, the samples have not to be coated with metal layers (electrodes), measurements at high temperatures are not affected by foreign chemical diffusion or bad electrical signal transmission.

Plates of $X(100)$ and $Z(001)$ simple orientations produced from $\alpha-\mathrm{GaPO}_{4}$ single crystals obtained by slow cooling from 950 to $600{ }^{\circ} \mathrm{C}$ in $\mathrm{X}_{2} \mathrm{O}: 3 \mathrm{MoO}_{3}$ fluxes $(\mathrm{X}=\mathrm{Li}, \mathrm{K})$ were used to follow the thermal evolution of $C^{\mathrm{D}}{ }_{11}$ and $C^{\mathrm{E}}{ }_{33}$ elastic constant [90]. $C^{\mathrm{D}}{ }_{11}$ was measured from room temperature up to $1000{ }^{\circ} \mathrm{C}$ to follow the $\alpha$-quartz/ $\beta$-cristobalite phase transition found close to $970{ }^{\circ} \mathrm{C}$, in good agreement with other thermal studies [30,41,42,44,46,89,101]. $C_{33}^{\mathrm{E}}$ presented a monotonous decrease with temperature up to $850{ }^{\circ} \mathrm{C}$ while $C^{\mathrm{D}}{ }_{11}$ presented a slight variation over the $20-500{ }^{\circ} \mathrm{C}$ temperature range followed by a stronger variation when approaching the phase transition temperature at $970{ }^{\circ} \mathrm{C}[90]$.

For the Brillouin scattering measurements using the backscattering geometry undertaken on a $\alpha-\mathrm{GaPO}_{4}$ crystal shaped as a cube with $X$-, $Y$ - and $Z$-faces [103], the $C^{\mathrm{E}}{ }_{11}, C^{\mathrm{E}}{ }_{33}, C^{\mathrm{E}}{ }_{44}$ and $C^{\mathrm{E}}{ }_{12}$ constants showed monotonic elastic softening upon heating up to $850{ }^{\circ} \mathrm{C}$ while $C^{\mathrm{E}}{ }_{66}$ and $C^{\mathrm{E}}{ }_{14}$ showed continuous stiffening. Most of the $C_{I J}$ elastic stiffness constant derives by only a few percent upon heating, while $C^{\mathrm{E}}{ }_{14}$ increases by about $50 \%$ and $C^{\mathrm{E}}{ }_{12}$ decreases by about $35 \%$. The first-order temperature coefficients $T^{(1)}{ }_{C I J}$ were negative for $C^{\mathrm{E}}{ }_{11}, C^{\mathrm{E}}{ }_{33}, C^{\mathrm{E}}{ }_{44}$ and $C^{\mathrm{E}}{ }_{12}$ elastic constants [103] in perfect agreement with previous reports on hydrothermally-grown $\alpha-\mathrm{GaPO}_{4}$ crystals $[67,110,112,118]$.

\subsubsection{Flux-Grown $\alpha-\mathrm{GeO}_{2}$}

Different sets of $C_{I J}$ elastic stiffness constants at constant electric displacement and ambient conditions have been reported on flux- and hydrothermally-grown $\alpha-\mathrm{GeO}_{2}$ [23,24,109,116]. However, only one set of elastic data concerning their thermal evolution is reported in the literature [109]. It concerns a high resolution Brillouin scattering study of $\mathrm{MoO}_{3}$-based flux-grown $\alpha-\mathrm{GeO}_{2}$ single crystals from room temperature up to $1000{ }^{\circ} \mathrm{C}$. Any accident as discontinuity or phase transition was registered on the thermal evolution of the elastic constants in agreement with the conservation of the $\alpha$-quartz-like structure of flux-grown $\mathrm{GeO}_{2}$ material up to melting $\left(1116{ }^{\circ} \mathrm{C}\right)[93,94]$. The $C_{11}, C_{33}$, and $C_{12}$ elastic constants show monotonic elastic softening upon heating while $C_{44}$ and $C_{66}$ show continuous stiffening.

The thermal evolution of the $\mathrm{e}_{11}^{2} / \varepsilon_{11}$ piezoelectric term, deduced from the difference between $C^{\mathrm{D}}{ }_{11}$ and $C^{\mathrm{E}}{ }_{11}$, was found stable up to $1000{ }^{\circ} \mathrm{C}$, Figure 4 [93,109] meaning that $\mathrm{MoO}_{3}$-based flux-grown $\alpha-\mathrm{GeO}_{2}$ crystals exhibit piezoelectric activity even at very high temperature. 
Figure 4. Thermal dependence of pure and piezoelectrically stiffened $C_{11}$ elastic constant of flux-grown $\alpha-\mathrm{GeO}_{2}$. Errors are smaller than the symbol size.

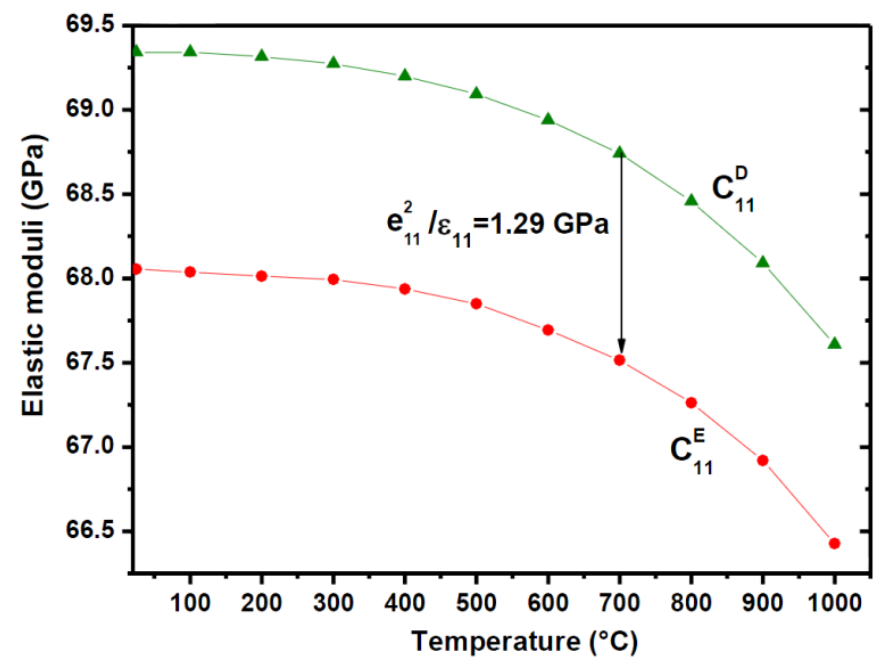

\section{Conclusions}

In the family of $\alpha$-quartz isotypes, high quality $\alpha-\mathrm{GaPO}_{4}$ and $\alpha-\mathrm{GeO}_{2}$ single crystals with a larger thermal stability and higher piezoelectric properties than $\alpha$-quartz can potentially be used as piezoelectric materials for high temperatures applications. However if these single crystals are grown via hydrothermal-based methods, the presence of significant numbers of hydroxyl groups and structural defects in their network lead to a degradation of their physical properties and even to a phase transformation at relatively low temperature for $\alpha-\mathrm{GeO}_{2}$.

The main structural and chemical results obtained from infrared studies ( $\mathrm{OH}$-content), thermal behavior analysis and Brillouin scattering experiments on $\mathrm{MoO}_{3}$-based flux-grown $\alpha-\mathrm{GaPO}_{4}$ and $\alpha-\mathrm{GeO}_{2}$ single-crystals have demonstrated $\mathrm{OH}$-free high quality piezoelectric crystals and an improved thermal stability.

These results confirm on one hand the high potential of flux-grown $\alpha-\mathrm{GaPO}_{4}$ and $\alpha-\mathrm{GeO}_{2}$ single crystals as piezoelectric materials for high temperature applications and on the other hand a very powerful method of high temperature flux melted technique to grow high quality $\alpha$-quartz isotype single crystals.

Moreover, as iso-structural to $\alpha$-quartz, most of the device designs developed for $\alpha$-quartz single crystal could be applied for $\alpha-\mathrm{GeO}_{2}$ with minor adaptations. The potential of $\alpha-\mathrm{GeO}_{2}$ single crystal for the realization of piezoelectric devices is also confirmed as its $d_{11}$ piezoelectric constant at ambient temperature is found to be more than twice that of $\alpha$-quartz. The piezoelectric property of $\alpha-\mathrm{GeO}_{2}$ is still conserved at high temperature as a significant piezoelectric contribution to $C_{11}$ still exists at $1000{ }^{\circ} \mathrm{C}$.

\section{Author Contributions}

Pascale Armand, Adrien Lignie and Marion Beaurain performed crystal growths of flux-grown piezoelectric materials, characterizations and data analysis. All author discussed the results and Pascale Armand wrote the paper. 


\section{Conflicts of Interest}

The authors declare no conflict of interest.

\section{References}

1. Zhang, S.; Yu, F. Piezoelectric materials for high temperature sensors. J. Am. Ceram. Soc. 2011, 94, 3153-3170.

2. Jiang, X.; Kim, K.; Zhang, S.; Johnson, J.; Salazar, F. High temperature piezoelectric sensing. Sensors 2014, 14, 144-169.

3. Smith, G.S.; Alexander, L.E. Refinement of the atomic parameters of $\alpha$-quartz. Acta Cryst. 1963, $16,462-471$.

4. Smith, G.S.; Isaacs, P.B. The crystal structure of quartz-like $\mathrm{GeO}_{2}$. Acta Cryst. 1964, 17, 842-846.

5. Le Page, Y.; Donnay, G. Refinement of the crystal structure of low-quartz. Acta Cryst. 1976, B32, 2456-2459.

6. Le Page, Y.; Calvert, L.D.; Gabe, E.J. Parameter variation in low-quartz between 94 and 298 K. J. Phys. Chem. Solids 1980, 41, 721-725.

7. Goiffon, A.; Bayle, G.; Astier, R.; Jumas, J.-C.; Maurin, M.; Philippot, E. Cristallochimie des phases $\mathrm{GaPO}_{4}, \mathrm{AlAsO}_{4}$ et $\mathrm{GaAsO}_{4}$. Etude comparée des structures de type quartz- $\alpha$. Rev. Chim. Minér. 1983, 20, 338-350. (In French)

8. Goiffon, A.; Jumas, J.-C.; Philippot, E. Phases de type quartz $\alpha$ : Structure de $\mathrm{FePO}_{4}$ et spectrométrie Mössbauer du fer-57. Rev. Chim. Minér. 1986, 23, 99-109. (In French)

9. Goiffon, A.; Jumas, J.-C.; Maurin, M.; Philippot, E. Etude comparée à diverses températures $(173,293$ et $373 \mathrm{~K})$ des structures de type quartz $\alpha$ des phases $\mathrm{MXO}_{4}\left(\mathrm{M}^{\mathrm{III}}=\mathrm{Al}\right.$, Ga et $\left.\mathrm{X}^{\mathrm{V}}=\mathrm{P}, \mathrm{As}\right)$. J. Solid State Chem. 1986, 61, 384-396. (In French)

10. Glinnemann, J.; King, H.E.; Schulz, H.; Hahn, Th.; la Placa, S.J.; Dacol, F. Crystal structures of the low-temperature quartz-type phases of $\mathrm{SiO}_{2}$ and $\mathrm{GeO}_{2}$ at elevated pressure. Z. Kristall. 1992, $198,177-212$.

11. Haines, J.; Cambon, O.; Philippot, E.; Chapon, L.; Hull, S. A neutron diffraction study of the thermal stability of the $\alpha$-quartz-type structure in germanium dioxide. J. Solid State Chem. 2002, $166,434-441$.

12. Guillot, R.; Fertey, P.; Hansen, N.K.; Allé, P.; Elkaïm, E.; Lecomte, C. Diffraction study of the piezoelectric properties of low quartz. Eur. Phys. J. B 2004, 42, 373-380.

13. Haines, J.; Cambon, O.; Prudhomme, N.; Fraysse, G.; Keen, D.A.; Chapon, L.C.; Tucker, M.G. High-temperature, structural disorder, phase transitions, and piezoelectric properties of $\mathrm{GaPO}_{4}$. Phys. Rev. B 2006, 73, 014103:1-014103:10.

14. Labéguerie, P.; Harb, M.; Baraille, I.; Rérat, M. Structural electronic, elastic, and piezoelectric properties of $\alpha$-quartz and $\mathrm{MXO}_{4}(\mathrm{M}=\mathrm{Al}, \mathrm{Ga}, \mathrm{Fe} ; \mathrm{X}=\mathrm{P}, \mathrm{As})$ isomorph compounds: A DFT study. Phys. Rev. B 2010, 81, 045107:1-045107:9. 
15. Giangrisostomi, E.; Minicucci, M.; Trapananti, A.; di Cicco, A. Multiple-scattering X-ray absorption analysis of quartz-like, rutile-like, and amorphous germanium dioxide. Phys. Rev. B 2011, 84, 214202:1-214202:8.

16. Lignie, A.; Granier, D.; Armand, P.; Haines, J.; Papet, P. Modulation of quartz-like $\mathrm{GeO}_{2}$ structure by Si substitution: An X-ray diffraction study of $\mathrm{Ge}_{1-x} \mathrm{Si}_{x} \mathrm{O}_{2}(0 \leq x<0.2)$ flux-grown single crystals. J. Appl. Cryst. 2012, 45, 272-278.

17. Philippot, E.; Palmier, D.; Pintard, M.; Goiffon, A. A general survey of quartz and quartz-like materials: Packing distortions, temperature, and pressure effects. J. Solid State Chem. 1996, 123, $1-13$.

18. Philippot, E.; Armand, P.; Yot, P.; Cambon, O.; Goiffon, A.; McIntyre, G.J.; Bordet, P. Neutron and X-ray structure refinements between 15 and $1073 \mathrm{~K}$ of piezoelectric gallium arsenate, $\mathrm{GaAsO}_{4}$ : Temperature and pressure behavior compared with other $\alpha$-quartz materials. J. Solid State Chem. 1999, 146, 114-123.

19. Grimm, H.; Dorner, B. On the mechanism of the $\alpha-\beta$ phase transformation of quartz. J. Phys. Chem. Solids 1975, 36, 407-413.

20. Zwijnenburg, M.A.; Huenerbein, R.; Bell, R.G.; Cora, F. A computational study into the (tetrahedral) distortion of $\mathrm{TX}_{2} \alpha$-quartz materials: The effect of changing the chemical composition away from $\mathrm{SiO}_{2}$. J. Solid State Chem. 2006, 179, 3429-3436.

21. Kihara, K. An X-ray study of the temperature dependence of the quartz structure. Eur. J. Mineral. 1990, 2, 63-77.

22. Philippot, E.; Goiffon, A.; Ibanez, A.; Pintard, M. Structure deformations and existence of the $\alpha-\beta$ transition in $\mathrm{MXO}_{4}$ quartz-like materials. J. Solid State Chem. 1994, 110, 356-362.

23. Balitsy, D.V.; Sil'vestrova, O.Y.; Balitsky, V.S.; Pisarevsky, Y.V.; Pushcharovsky, D.Y.; Philippot, E. Elastic, piezoelectric, and dielectric properties of $\alpha-\mathrm{GeO}_{2}$ single crystals. Crystallogr. Rep. 2000, 45, 145-147.

24. Pisarevsky, Y.V.; Silvestrova, O.Y.; Philippot, E.; Balitsky, D.V.; Pisharovsky, D.Y.; Balitsky, V.S. Piezoelectric, Dielectric and Elastic Properties of Germanium Dioxide Single Crystals. In Proceedings of the 2000 IEEE/EIA International Frequency Control Symposium and Exhibition, Kansas City, MO, USA, 7-9 June 2000.

25. Cambon, O.; Haines, J. Structure-piezoelectric Property Relationships in $\alpha$-Quartz Isotypes: Design and Characterization of High Performance Piezoelectric Materials. In Proceedings of the 2003 IEEE International Frequency Control Symposium, Frequency Control Symposium and PDA Exhibition Jointly with the 17th European Frequency and Time Forum, Tampa, FL, USA, 4-8 May 2003.

26. Cambon, O.; Haines, J.; Fraysse, G.; Détaint, J.; Capelle, B.; van der Lee, A. Piezoelectric characterization and thermal stability of a high-performance $\alpha$-quartz-type material, gallium arsenate. J. Appl. Phys. 2005, 97, 074110:1-074110:7.

27. Lignie, A.; Ménaert, B.; Armand, P.; Pena, A.; Debray, J.; Papet, P. Top seeded solution growth and structural characterizations of $\alpha$-quartz-like structure $\mathrm{GeO}_{2}$ single crystal. Cryst. Growth Des. 2013, 13, 4220-4225.

28. Engel, G.F.; Krempl, P.W. Stability of $\alpha$-phases of quartz-isomorphs. Ferroelectrics 1984, 54, $9-12$. 
29. Kolodiev, B.N.; Makhina, I.B. $\mathrm{GeO}_{2}-\mathrm{A}$ promising new piezoelectric. Sov. Phys. Crystallogr. 1989, 34, 455-456.

30. Laubengayer, A.W.; Morton, D.S. The polymorphism of germanium dioxide. J. Am. Chem. Soc. 1932, 54, 2303-2320.

31. Baur, W.H.; Khan, A.A. Rutile-type compounds. IV. $\mathrm{SiO}_{2}, \mathrm{GeO}_{2}$ and a comparison with other rutile-type structures. Acta Cryst. 1971, B27, 2133-2139.

32. Rao, K.V.K.; Naidu, S.V.N.; Iyengar, L. Precision lattice parameters and the coefficients of thermal expansion of hexagonal germanium dioxide. J. Appl. Cryst. 1973, 6, 136-138.

33. Yamanaka, T.; Kurashima, R.; Mimaki, J. X-ray diffraction study of bond character of rutile-type $\mathrm{SiO}_{2}, \mathrm{GeO}_{2}$ and $\mathrm{SnO}_{2}$. Z. Kristallogr. 2000, 215, 424-428.

34. Micoulaut, M.; Cormier, L.; Henderson, G.S. The structure of amorphous, crystalline and liquid $\mathrm{GeO}_{2}$. J. Phys. Condens. Matter 2006, 18, R753-R784.

35. Madon, M.; Gillet, P.; Julien, C.; Price, G.D. A vibrational study of phase transitions among the $\mathrm{GeO}_{2}$ polymorphs. Phys. Chem. Miner. 1991, 18, 7-18.

36. Kotera, Y.; Yonemura, M. Kinetics of the transformation of germanium oxide. Trans. Faraday Soc. 1963, 59, 147-155.

37. Newns, G.R.; Hanks, R. Thermal behavior of germanium dioxide. J. Chem. Soc. A 1966, 954-957.

38. Sarver, J.F. Polymorphism and subsolidus equilibria in the system $\mathrm{GeO}_{2}-\mathrm{TiO}_{2}$. Am. J. Sci. 1961, 259, 709-718.

39. Bielz, T.; Soisuwan, S.; Kaindl, R.; Tessadri, R.; Többens, D.M.; Klötzer, B.; Penner, S. A high-resolution diffraction and spectroscopic study of the low-temperature phase transformation of hexagonal to tetragonal $\mathrm{GeO}_{2}$ with and without alkali hydroxide promotion. $J$. Phys. Chem. C 2011, 115, 9706-9712.

40. Perloff, A. Temperature inversions of anhydrous gallium orthophosphate. J. Am. Ceram. Soc. 1956, 39, 83-88.

41. Barz, R.-U.; Schneider, J.; Gille, P. High-temperature phase transitions of gallium orthophosphate $\left(\mathrm{GaPO}_{4}\right)$. Z. Kristallogr. 1999, 214, 845-849.

42. Jacobs, K.; Hofmann, P.; Klimm, D.; Reichow, J.; Schneider, M. Structural phase transformations in crystalline gallium orthophosphate. Solid State Chem. 2000, 149, 180-188.

43. Pey, F. Synthèse et Caractérisations de Matériaux Homéotypes du Quartz. Ph.D. Thesis, Université Montpellier II, Montpellier, France, October 2004. (In French)

44. Beaurain, M.; Armand, P.; Papet, P. Synthesis and characterization of $\alpha-\mathrm{GaPO}_{4}$ single crystals grown by the flux method. J. Cryst. Growth 2006, 294, 396-400.

45. Angot, E.; le Parc, R.; Levelut, C.; Beaurain, M.; Armand, P.; Cambon, O.; Haines, J. A high temperature Raman scattering study of the phase transitions in $\mathrm{GaPO}_{4}$ and the $\mathrm{AlPO}_{4}-\mathrm{GaPO}_{4}$ system. J. Phys. Condens. Matter 2006, 18, 4315-4327.

46. Beaurain, M.; Armand, P.; Balitsky, D.; Papet, P. Physical Characterizations of $\alpha-\mathrm{GaPO}_{4}$ Single Crystals Grown by the Flux Method. In Proceedings of the 2007 Joint Meeting of the European Time and Frequency Forum (EFTF) and the IEEE International Frequency Control Symposium (IEEE-FCS), Geneva, Switzerland, 29 May-1 June 2007. 
47. Hirano, S.; Miwa, K.; Naka, S. Hydrothermal synthesis of gallium orthophosphate crystals. $J$. Cryst. Growth 1986, 79, 215-218.

48. Hirano, S.; Kim, P. Hydrothermal synthesis of gallium orthophosphate crystals. Bull. Chem. Soc. Jpn. 1989, 62, 275-278.

49. Engel, G.; Klapper, H.; Krempl, P.; Mang, H. Growth twinning in quartz-homeotypic gallium orthophosphate crystals. J. Cryst. Growth 1989, 94, 597-606.

50. Cochez, M. Cristallogénèse et Caractérisations du Phosphate de Gallium, $\mathrm{GaPO}_{4}$, Matériau Piézoélectrique à Fort Coefficient de Couplage. Ph.D. Thesis, Université Montpellier II, Montpellier, France, September 1994. (In French)

51. Hirano, S.; Kim, P.C. Growth of gallium orthophosphate single crystals in acidic hydrothermal solutions. J. Mater. Sci. 1991, 26, 2805-2808.

52. Philippot, E.; Ibanez, A.; Goiffon, A.; Cochez, M.; Zarka, A.; Capelle, B.; Schwartzel, J.; Détaint, J. A quartz-like material: Gallium phosphate $\left(\mathrm{GaPO}_{4}\right)$; crystal growth and characterization. J. Cryst. Growth 1993, 130, 195-208.

53. Palmier, D.; Goiffon, A.; Capelle, B.; Détaint, J.; Philippot, E. Crystal growth and characterization of quartz-like material: Gallium phosphate $\left(\mathrm{GaPO}_{4}\right)$. J. Cryst. Growth 1996, 166, 347-353.

54. Motchany, A.I.; Chvanski, P.P.; Leonyuk, N.I. Synthesis and solubility of $\mathrm{GaPO}_{4}$ crystals in acid solutions under hydrothermal conditions. J. Cryst. Growth 2000, 211, 506-508.

55. Yot, P.; Cambon, O.; Balitsky, D.; Goiffon, A.; Philippot, E.; Capelle, B.; Détaint, J. Advances in crystal growth and characterizations of gallium phosphate, $\mathrm{GaPO}_{4}$. J. Cryst. Growth 2001, 224, 294-302.

56. Demianets, L.N. Gallium orthophosphate hydrothermal growth at high temperatures $\left(320{ }^{\circ} \mathrm{C}\right)$. Ann. Chim. Sci. Mater. 2001, 26, 67-74.

57. Jacobs, K.; Hofmann, P.; Reichow, J. Physico-chemical aspects of the hydrothermal growth of $\mathrm{GaPO}_{4}$. Ann. Chim. Sci. Mater. 2001, 26, 85-90.

58. Barz, R.-U.; Grassl, M.; Gille, P. Study of anisotropic effects in hydrothermal growth of gallium orthophosphate single crystals. Ann. Chim. Sci. Mater. 2001, 26, 95-98.

59. Grassel, M.; Barz, R.-U.; Gille, P. Reducing inversion twinning in single crystal growth of $\mathrm{GaPO}_{4}$. Cryst. Res. Technol. 2002, 37, 531-539.

60. Barz, R.-U.; Grassel, M.; Gille, P. Studies on the solubility of $\mathrm{GaPO}_{4}$ in phosphoric acid. $J$. Cryst. Growth 2002, 245, 273-277.

61. Balitsky, D.V.; Philippot, E.; Papet, P.; Balitsky, V.S.; Pey, F. Comparative crystal growth of $\mathrm{GaPO}_{4}$ crystals in the retrograde and direct solubility range by hydrothermal methods of temperature gradient. J. Cryst. Growth 2005, 275, e887-e894.

62. Byrappa, K.; Yoshimura, M. Hydrothermal Growth of Some Selected Crystals. In Handbook of Hydrothermal Technology, 2nd ed.; Noyes Publications: Park Ridge, NJ, USA; William Andrew Publishing, LLC: Norwich, NY, USA, 2001.

63. Philippot, E.; Goiffon, A.; Maurin, M.; Détaint, J.; Schwartzel, J.; Toudic, B.; Capelle, B.; Zarka, A. Evaluation of high quality berlinite crystals grown in sulphuric acid medium. J. Cryst. Growth 1990, 104, 713-726.

64. Zvereva, O.V.; Demianets, L.N. Substrate orientation and hydrothermal growth of $\mathrm{GaPO}_{4}$ single crystals. Crystallogr. Rep. 1995, 40, 990-993. 
65. Krispel, F.; Krempl, P.W.; Knoll, P.; Wallnöfer, W. OH Impurities in Gallium Phosphate. In Proceedings of the 11th European Frequency and Time Forum, Neuchâtel, Switzerland, 4-6 March 1997.

66. Détaint, J.; Zarka, A.; Capelle, B.; Palmier, D.; Philippot, E. Optimisation of the Design of the Resonators Using the New Materials: Application to Gallium Phosphate and Langasite. In Proceedings of the 1997 IEEE International, Orlando, FL, USA, 28-30 May 1997.

67. Palmier, D. Optimisation de la Cristallogénèse et de la Caractérisation des Propriétés Piézoélectriques du Phosphate de gallium. Ph.D. Thesis, Université Montpellier II, Montpellier, France, November 1996. (In French)

68. Marhino, E.; Palmier, D.; Goiffon, A.; Philippot, E. Spatial-OH impurity distribution in gallium phosphate crystals. J. Mater. Sci. 1998, 33, 2825-2830.

69. Wallnöfer, W.; Krempl, P.W.; Krispel, F.; Willfurth, V. Segregation forming and growth defect characterization by heat treatment of hydrothermally grown $\mathrm{GaPO}_{4}$. J. Cryst. Growth 1999, 198-199, 487-491.

70. Grassl, M.; Barz, R.-U.; Gille, P. Etch studies on $\mathrm{GaPO}_{4}$ single crystals. J. Cryst. Growth 2000, 220, 522-530.

71. Jacobs, K.; Hofmann, P.; Klimm, D. OH impurities in $\mathrm{GaPO}_{4}$ crystals: Correlation between infrared absorption and mass loss during thermal treatment. J. Cryst. Growth 2002, 237-239, 837-842.

72. Prud'homme, N. Cristallisation-dissolution de $\mathrm{GaPO}_{4}$ : Phénomènes à l'interface Cristal-Solvant. Etude de la Dissolution Contrôlée de $\mathrm{GaPO}_{4}$ pour la Réalisation de Résonateurs Piézoélectriques à Haute Fréquence. Ph.D. Thesis, Université Montpellier II, Montpellier, France, December 2005. (In French)

73. Hofmann, P.; Juda, U.; Jacobs, K. Characterization of etch figures on as-grown surfaces of $\mathrm{GaPO}_{4}$ crystals. J. Cryst. Growth 2005, 275, e1883-e1888.

74. Defregger, S.; Engel, G.F.; Krempl, P.W. Linear and nonlinear optical properties of quartz-type $\mathrm{GaPO}_{4}$. Phys. Rev. B 1991, 43, 6733-6738.

75. Barz, R.U.; Ghemen, S.V. Water-free gallium phosphate single-crystal growth from the flux. $J$. Cryst. Growth 2005, 275, e921-e926.

76. Hill, V.G.; Chang, L.L.Y. Hydrothermal investigation of $\mathrm{GeO}_{2}$. Am. Miner. 1968, 53, 1744-1748.

77. Roy, R.; Theokritoff, S. Crystal growth of metastable phases. J. Cryst. Growth 1972, 12, 69-72.

78. Demianets, L.N. Hydrothermal synthesis of new compounds. Prog. Cryst. Growth Charact. 1990, 22, 299-355.

79. Glushkova, T.M.; Kiselev, D.F.; Makhina, I.B.; Firsova, M.M.; Shtyrkova, A.P. Trigonal germanium dioxide: Its preparation and optical parameters. Moscow Univ. Phys. Bull. 1992, 47, $55-58$.

80. Balitsky, D.V.; Balitsky, V.S.; Pisarevley, Y.V.; Philippot, E.; Silvestrova, O.Y.; Pushcharovsky, D.Y. Growth of germanium dioxide single crystals with $\alpha$-quartz structure and investigation of their crystal structure, optical, elastic, piezoelectric, dielectric and mechanical properties. Ann. Chim. Sci. Mater. 2001, 26, 183-192. 
81. Balitsky, D.V.; Balitsky, V.S.; Pushcharovsky, D.Y.; Bondarenko, G.V.; Kosenko, A.V. Growth and characterization of $\mathrm{GeO}_{2}$ single crystals with the quartz structure. J. Cryst. Growth 1997, 180, 212-219.

82. Laurent, Y. Obtention de monocristaux au sein d'un flux fondu. Rev. Chim. Miner. 1969, 6, 1145-1186. (In French)

83. Elwell, D.; Neate, B.W. Review: Mechanisms of crystal growth from fluxed melts. J. Mater. Sci. 1971, 6, 1499-1519.

84. Tolksdorf, W. Crystal growth and epitaxy from high-temperature solutions. In Synthesis, Crystal Growth and Characterization; Lal, K., Ed.; North-Holland: Oxford, UK, 1982; pp. 197-211.

85. Nielse, J.W. Recent development in crystal growth from high-temperature solutions. In Growth of Crystals; Chernov, A.A., Ed.; Consultant Bureau: New York, NY, USA, 1984; Volume 12, pp. 143-154.

86. Roy, R.; White, W.B. High temperature solution (flux) and high pressure solution (hydrothermal) crystal growth. J. Cryst. Growth 1968, 3-4, 33-42.

87. Beaurain, M.; Armand, P.; Papet, P. Growth of piezoelectric single crystals by the flux method. J. Cryst. Growth 2005, 2975, e279-e282.

88. Shvanskii, E.; Armand, P.; Balitsky, D.; Philippot, E.; Papet, E. Flux growth gallium orthophosphate crystals. Ann. Chim. Sci. Mater. 2006, 31, 97-102.

89. Beaurain, M. Monocristaux de $\alpha-\mathrm{GaPO}_{4}$ : Croissance par la Technique du Flux et Caractérisations Physiques. Ph.D. Thesis, Université Montpellier II, Montpellier, France, December 2006. (In French)

90. Armand, P.; Beaurain, M.; Rufflé, B.; Ménaert, B.; Balitsky, D.; Clément, S.; Papet, P. Characterizations of piezoelectric $\mathrm{GaPO}_{4}$ single crystals grown by the flux method. J. Cryst. Growth 2008, 310, 1455-1459.

91. Finch, C.B.; Clark, G.W. Flux growth and characterization of hexagonal germanium dioxide single crystals. Am. Miner. 1968, 53, 1394-1398.

92. Goodrum, J.W. Solution top-seeding: Growth of $\mathrm{GeO}_{2}$ polymorphs. J. Cryst. Growth 1972, 13-14, 604-607.

93. Lignie, A. Matériaux Piézoélectriques Pour Applications Hautes Températures: Etude de la Croissance de Monocristaux de $\mathrm{Ge}_{1-x} \mathrm{Si}_{x} \mathrm{O}_{2}(0 \leq x \leq 0,2)$ et de Leurs Propriétés. Ph.D. Thesis, Université Montpellier II, Montpellier, France, September 2012. (In French)

94. Lignie, A.; Armand, P.; Papet, P. Growth of piezoelectric water-free $\mathrm{GeO}_{2}$ and $\mathrm{SiO}_{2}$-substituted $\mathrm{GeO}_{2}$ single-crystals. Inorg. Chem. 2011, 50, 9311-9317.

95. Tarr, W.A.; Lonsdale, J.T. Pseudo-cubic quartz crystals from Artesia, New Mexico. Am. Miner. 1929, 14, 50-53.

96. Hartman, P. Sur la morphologie des cristaux. Bull. Miner. 1978, 101, 195-201. (In French)

97. Iwasaki, H.; Iwasaki, F. Morphological variations of quartz crystals as deduced from computer experiments. J. Cryst. Growth 1995, 151, 348-358.

98. Philippot, E.; Goiffon, A.; Ibanez, A. Comparative crystal habit study of quartz and $\mathrm{MPO}_{4}$ isomorphous compounds ( $\mathrm{M}=\mathrm{Al}, \mathrm{Ga})$. J. Cryst. Growth 1996, 160, 268-278. 
99. Philippot, E.; Ibanez, A.; Goiffon, A.; Capelle, B.; Zarka, A.; Schwartzel, J.; Détaint, J. Crystal Growth and Physical Characterizations of $\mathrm{GaPO}_{4}$. In Proceedings of the 6th European Frequency and Time Forum, Noordwijk, NL, USA, 17-19 March 1992.

100. Cochez, M.; Ibanez, A.; Goiffon, A.; Philippot, E. Crystal growth and infrared characterization of $\mathrm{GaPO}_{4}$ in phosphoric-sulphuric media. Eur. J. Solid State Inorg. Chem. 1993, 30, 509-519.

101. Beaurain, M.; Armand, P.; Papet, P. Growth of $\alpha-\mathrm{GaPO}_{4}$ and $\alpha-\mathrm{GeO}_{2}$ single crystals by the flux method. J. Phys. IV 2005, 126, 23-26.

102. Krempl, P.W.; Krispel, F.; Wallnöfer, W.; Leuprecht, G. $\mathrm{GaPO}_{4}$ : A Critical Review of Material Data. In Proceedings of the Ninth European Frequency and Time Forum, Besançon, France, 8-10 March 1995.

103. Armand, P.; Beaurain, M.; Rufflé, B.; Ménaert, B.; Papet, P. Temperature dependence of single-crystal elastic constants of flux-grown $\alpha-\mathrm{GaPO}_{4}$. Inorg. Chem. 2009, 48, 4988-4996.

104. Sendova-Vassileva, M.; Tzenov, N.; Dimova-Malinovskia, D.; Rosenbauer, M.; Stutzmann, M.; Josepovits, K.V. Structural and luminescence studies of stain-etched and electrochemically etched germanium. Thin Solid Films 1995, 255, 282-285.

105. Kaindl, R.; Többens, D.M.; Penner, S.; Bielz, T.; Soisuwan, S.; Klötzer, B. Quantum mechanical calculations of the vibrational spectra of quartz- and rutile-type $\mathrm{GeO}_{2}$. Phys. Chem. Miner. 2012, $39,47-55$.

106. Fraysse, G.; Lignie, A.; Armand, P.; Bourgogne, D.; Haines, J.; Ménaert, B.; Papet, P. Vibrational origin of the thermal stability in the highly distorted $\alpha$-quartz type material $\mathrm{GeO}_{2}$ : An experimental and theoretical study. Inorg. Chem. 2013, 52, 7271-7279.

107. Hermet, P.; Fraysse, G.; Lignie, A.; Armand, P.; Papet, Ph. Density functional theory predictions of the nonlinear optical properties in $\alpha$-quartz-type germanium dioxide. J. Phys. Chem. C 2012, $116,8692-8698$.

108. Hermet, P.; Lignie, A.; Fraysse, G.; Armand, P.; Papet, P. Thermodynamic properties of the $\alpha$-quartz-type and rutile-type $\mathrm{GeO}_{2}$ from first-principles calculations. Phys. Chem. Chem. Phys. 2013, 15, 15943-15948.

109. Lignie, A.; Zhou, W.; Armand, P.; Rufflé, B.; Mayet, R.; Debray, J.; Hermet, P.; Ménaert, B.; Thomas, P.; Papet, P. High-temperature elastic moduli of flux-grown $\alpha-\mathrm{GeO}_{2}$ single crystal. ChemPhysChem 2014, 15, 118-125.

110. Beaurain, M.; Armand, P.; Detaint, J.; Ménaert, B.; Balitsky, D.; Papet, P. Elastic characterizations of the $\alpha-\mathrm{GaPO}_{4}$ single crystals grown by the flux method. J. Phys. Condens. Matter 2008, 20, 025226:1-025226:7.

111. Zhou, Y.; Liu, B. Theoretical investigation of mechanical and thermal properties of $\mathrm{MPO}_{4}$ $(\mathrm{M}=\mathrm{Al}$, Ga). J. Eur. Ceram. Soc. 2013, 33, 2817-2821.

112. Krempl, P.W.; Schleinzer, G.; Wallnöfer, W. Gallium phosphate: A new piezoelectric crystal material for high-temperature sensorics. Sens. Actuator A 1997, 61, 361-363.

113. Krempl, P.W.; Krispel, F.; Wallnöfer, W. Industrial development and prospects of $\mathrm{GaPO}_{4}$. Ann. Chim. Sci. Mater. 1997, 22, 623-626.

114. Ghobadi, E.; Capobianco, J.A. Crystal properties of $\alpha$-quartz type $\mathrm{GeO}_{2}$. Phys. Chem. Chem. Phys. 2000, 2, 5761-5763. 
115. Liu, Q.-J.; Liu, Z.-T.; Feng, L.-P.; Tian, H. First-principles study of structural, elastic, electronic and optical properties of rutile $\mathrm{GeO}_{2}$ and $\alpha$-quartz $\mathrm{GeO}_{2}$. Solid State Sci. 2010, 12, 1748-1755.

116. Grimsditch, M.; Polian, A.; Brazhkin, V.; Balitskii, D. Elastic constants of $\alpha-\mathrm{GeO}_{2}$. J. Appl. Phys. 1998, 83, 3018-3020.

117. Krempl, P.W. Piezoelectricity in quartz analogues. J. Phys. IV 2005, 126, 95-100.

118. Wallnöfer, W.; Stadler, J.; Krempl, P. Temperature Dependence of Elastic Constants of $\mathrm{GaPO}_{4}$ and Its Influence on BAW and SAW Devices. In Proceedings of the 7th European Frequency and Time Forum, Neuchâtel, Switzerland, 16-18 March 1993.

(C) 2014 by the authors; licensee MDPI, Basel, Switzerland. This article is an open access article distributed under the terms and conditions of the Creative Commons Attribution license (http://creativecommons.org/licenses/by/3.0/). 